\title{
RESPOSTA CLÍNICA AOS DIFERENTES ESQUEMAS TERAPÊUTICOS E DE SUPORTE NO TRATAMENTO DA CHIKUNGUNYA EM FEIRA DE SANTANA \\ Murilo Fernandes de Souza ${ }^{1}$; Erenilde Marques de Cerqueira ${ }^{2}$; Nadja Layane Gomes Santiago $^{3}$ e Melissa Barreto Falcão ${ }^{4}$ \\ 1. Bolsista CNPQ, membro do NUPEVS, Graduando em Medicina, Universidade Estadual de Feira de Santana, e- mail: murilofes@hotmail.com \\ 2. Orientadora, Coordenadora do NUPEVS, Departamento de Saúde, Universidade Estadual de Feira de Santana, e- mail: eremarques@fsonline.com.br \\ 3. Bolsista FAPESB, membro do NUPEVS, Graduanda em Medicina, Universidade Estadual de Feira de Santana, e- mail: nadjalayane@ hotmail.com \\ 4. Mestranda em Saúde Coletiva, membro do NUPEVS, Departamento de Saúde, Universidade Estadual de Feira de Santana, e-mail: melissa.falcao@ hotmail.com
}

\section{INTRODUÇÃO}

PALAVRAS-CHAVE: Chikungunya; tratamento; resposta clínica

O Chikungunya vírus (chikv) é um alphavirus transmitido principalmente pelos mosquitos Aedes aegypti, na zona urbana, e pelo Aedes albopictus, na zona rural (LEMANT et al., 2008). O ciclo de transmissão silvestre do chikv ocorre silenciosamente, com intervalos de latência de 3-4 anos, antes de ocorrerem os surtos da doença nas comunidades (BARRETT; WEAVER, 2002).

Nos últimos 50 anos tem ocorrido surtos frequentes de chikv na Ásia e África (BETTADAPURA et al., 2013). Segundo a Organização Pan-Americana da Saúde (2016), no fim de 2015, cerca de 1 milhão de casos tinham sido notificados nas Américas, resultando em 71 mortes, e a transmissão autóctone reportada em mais de 50 países. No Brasil, a transmissão dentro do território foi confirmada em setembro de 2014, no Amapá e em Feira de Santana-BA, tendo esta última 4088 notificações em 2015, representando quase $20 \%$ de todos os casos notificados no país (RODRIGUES, 2016). Nunes et al (2015) sugerem, em análises epidemiológicas, que aproximadamente 94\% da população brasileira está em risco de ser infectado pelo chikv.

Os sintomas da infecção por chikv incluem febre alta, calafrios, dor de cabeça, fotofobia e uma erupção petequial ou erupção cutânea maculopapular. Infecções assintomáticas podem ocorrer, mas são raras, sendo observada em cerca de $20 \%$ dos indivíduos infectados (LEMANT et al., 2008).

A doença possui um período de incubação de dois a doze dias, e pode manifestar-se clinicamente de três formas: aguda, subaguda e crônica. Na fase aguda, os sintomas são muito parecidos com aqueles da dengue, exceto a característica e a intensidade do comprometimento articular, mais frequente nas extremidades e grandes articulações; essa artrite/artralgia geralmente simétrica e intensa, podendo apresentar edema associado à rigidez e à limitação de movimento (BORGHERINI et al., 2007). A poliartralgia dolorosa é um sintoma típico e pode persistir em $10 \%$ dos casos por vários 
meses, causando sérios impactos econômicos e sociais individuais e para suas comunidades (PARASHAR; CHERIAN, 2014).

O tratamento é sintomático com analgésicos, antipiréticos e anti-inflamatórios não-esteroidais nas fases aguda e subaguda (BETTADAPURA et al., 2013). Na fase crônico associa-se o uso de corticoides e drogas usadas no tratamento de doenças reumáticas. O uso de terapias complementares também têm sido instituídas (fisioterapia, acupuntura e outras) no suporte e/ou tratamento da Chikungunya.

A alta possibilidade de ocorrência de epidemias no Brasil devido à grande densidade do vetor, à presença de indivíduos susceptíveis, à intensa circulação de pessoas em áreas endêmicas, à já instalada epidemia em Feira de Santana e cronificação de sintomas da doença ratificam a necessidade de avaliar as terapêuticas e suporte de tratamento instituído nas fases aguda, subaguda e crônica; e identificar possíveis fatores de cronificação da Chikungunya, na Rede de Saúde do município, a qual poderá ser sobrecarregada devido ao número elevado de pacientes que necessitam de atendimento.

Nesse sentido o presente trabalho apresentará uma amostra da terapêutica instituída em pacientes crônicos de Chikungunya, ainda na fase aguda, subaguda e crônica, relatadas pelos mesmos e por análise de prontuário da Secretaria Municipal de Saúde de Feira de Santana, bem como o estado clínico que os mesmos se apresentavam ao entrar no estudo.

\section{MATERIAL E MÉTODOS OU METODOLOGIA}

Pesquisa de natureza quantitativa, do tipo corte transversal, descritivo.

A população do estudo é composta pelos pacientes com sintomatologia compatível ao CHIKV, de aspecto crônico, duração maior que três meses, atendidos na Divisão de Vigilância Epidemiológica da Secretaria Municipal de Saúde (SMS) de Feira de Santana.

Foram incluídos neste estudo, pacientes com idade igual ou maior de 18 anos, com sintomas compatíveis com a definição de caso da doença, conforme preconizado pelo Ministério da Saúde (febre alta, artralgia, mialgia, cefaleias, calafrios, fotofobia e uma erupção petequial ou erupção cutânea maculopapular). Todos foram submetidos a teste de confirmação laboratorial. Todos os indivíduos selecionados foram submetidos a uma minuciosa avaliação clínica após terem assinado o TCLE.

Os dados foram registrados em planilha Microsoft Excel e em seguida exportados para o SPSS (Statistical Package for Social Science versão 10.0 for

Windows, SPSS Inc, Chicago,Illnois). A análise descritiva dos dados incluiu a distribuição de frequência das variáveis. 
O presente estudo é parte da pesquisa Chikungunya no município de Feira de Santana (BA), Brasil: Estudos clínicos, epidemiológicos, laboratoriais e de qualidade de vida. foi submetida e aprovada pelo Comitê de Ética em Pesquisa com Seres Humanos - CEP/UEFS sob protocolo n ${ }^{\circ} 1.450 .062$ obedecendo a Resolução 196/96 do Ministério da Saúde.

\section{RESULTADOS E/OU DISCUSSÃO}

No estudo clínico foram selecionados 22 pacientes que apresentavam sintomatologia crônica de Chinkungunya, ou seja, com persistência dos sinais e sintomas por mais de 3 meses. Todos tiveram o diagnóstico sorológico confirmado antes de serem selecionados para a pesquisa e desses 20 foram acompanhados e avaliados mensalmente para identificar a resposta a uma droga antimalárica usada em doenças reumáticas (hidroxicloroquina) em um projeto de mestrado em Saúde Coletiva. Vale salientar que dois indivíduos abandonaram o estudo.

Participaram da pesquisa, 17 mulheres e três homens, representando o sexo feminino $85 \%$ dos pacientes do estudo. Com seis indivíduos na faixa etária de 51-60 anos, cinco entre 61-70 anos, quatro entre 41-50 anos, três entre 31-40 anos, dois acima de 70 anos, sendo um com 74 anos e outro com 83 anos.

Em relação a cor da pele dos participantes, $40 \%$ eram brancos, igualmente $40 \%$ eram negros e $20 \%$ pardos. As profissões e ocupações dos participantes incluíram três: agentes comunitários de saúde, motoristas, donas de casa, vendedores; dois auxiliares em serviços gerais e dois aposentados, entre outras (costureira, merendeira, lavradora, cabelereira). Quanto a escolaridade, 30\% possuem ensino médio ou nível superior completos, sendo que 50\% apresenta nível fundamental incompleto.

A confirmação sorológica de $60 \%$ foi realizada através do Teste sorol identificada na fase crônica, IgG ChikV; e 40\% foram incluídos com resultados de IgM ChikV positivo, colhidos na fase aguda da infecção. Desses pacientes, 18 afirmaram não possuir nenhuma patológica reumatológica prévia, enquanto dois referiram artrose e rompimento de tendão previamente a doença.

Como comorbidade $75 \%$ dos pacientes eram diabéticos e/ou hipertensos e faziam uso de medicações para seus respectivos controles. Um indivíduo do estudo afirma ter desenvolvido estado depressivo devido as dores incapacitantes após evolução crônica do CHIKV. Todos os participantes apresentaram edema articular na avaliação inicial.

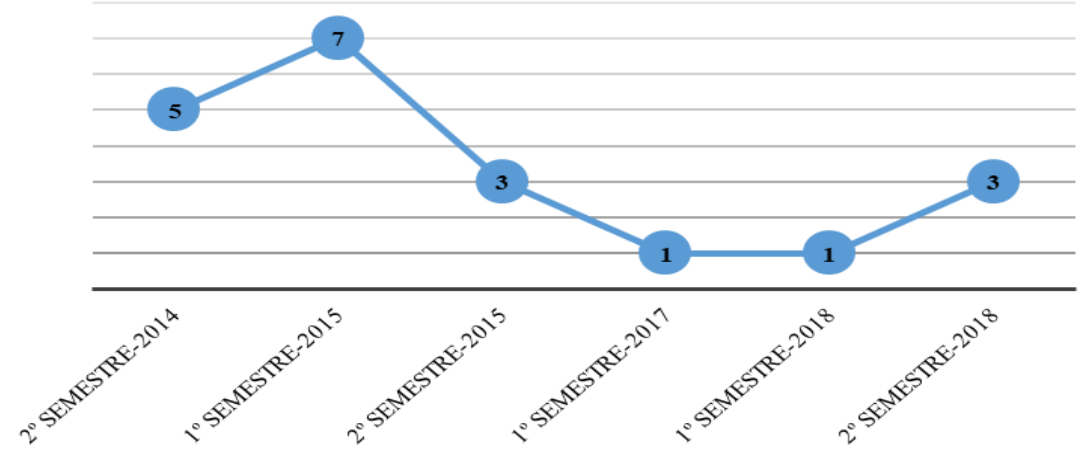

Figura 1: Número de indivíduos e período de início dos sinais e sintomas da infecção pelo CHIKV por INÍCIO DOS SINTOMAS semestre e ano. 


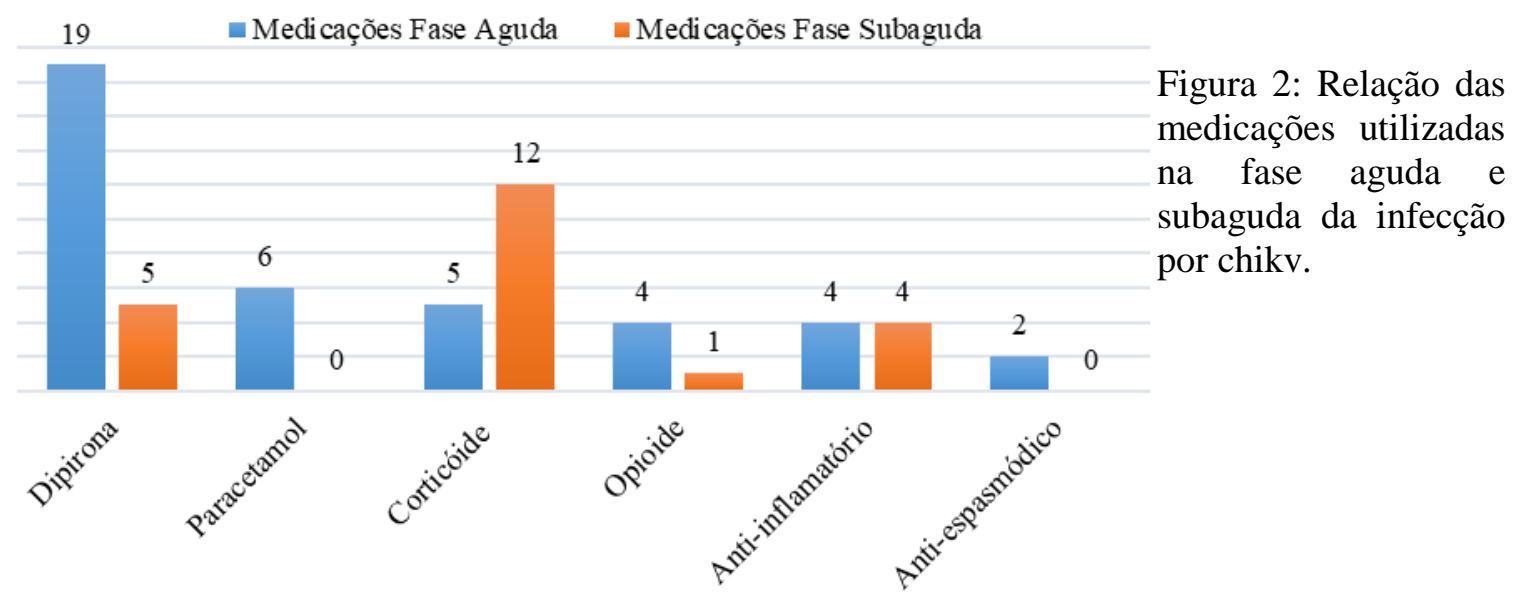

MEDICAÇÕES UTILIZADAS NA FASE AGUDA E SUBAGUDA
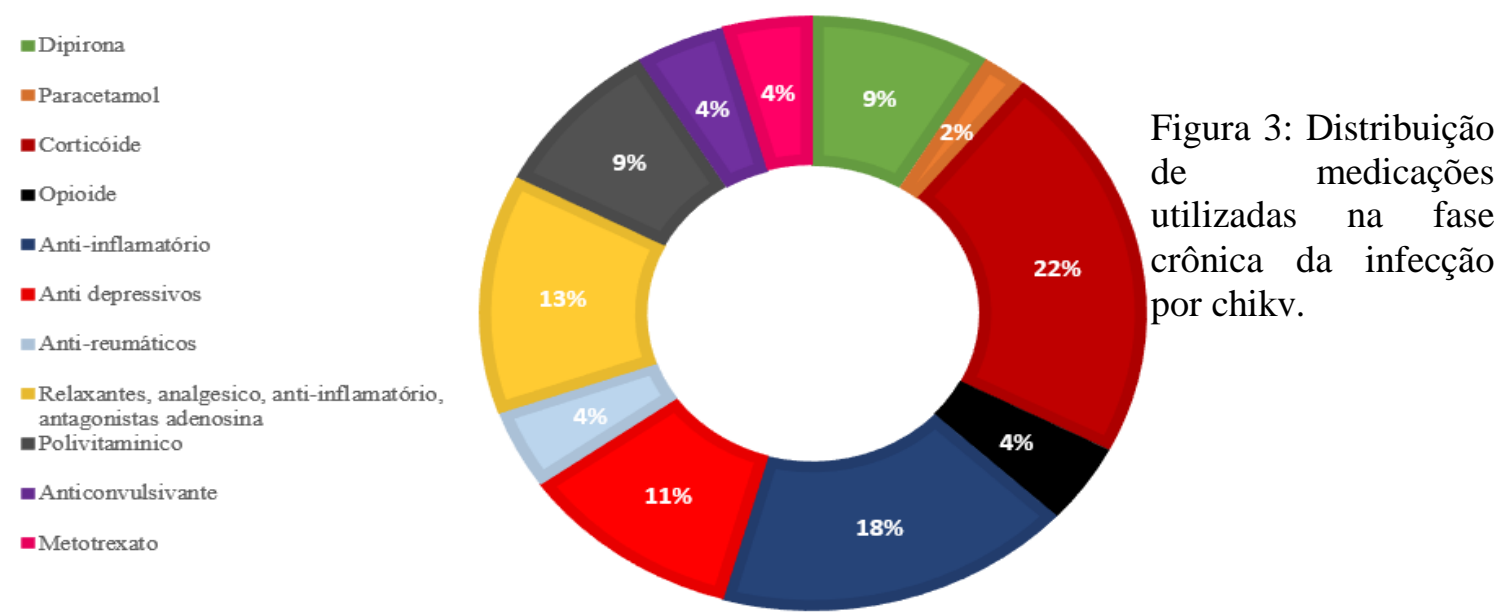

MEDICAÇÕES UTILIZADAS NA FASE CRÔNICA

Para avaliação da dor foi utilizada a escala visual analógica(EVA) de dor, 16 pacientes referiam dor intensa, classificada entre 8-10, seis classificaram como moderada entre 5-7. Na avaliação da fadiga, numa escala numérica de 0 a 10, 11 dos pesquisados classificaram como intensa e nove como moderada.

A rigidez articular foi avaliada de acordo com o tempo que o paciente demora para conseguir abrir os dedos das mãos ao acordar, assim um afirmou não apresentar rigidez matinal, seis possuíam rigidez que durava menos de $30 \mathrm{~min}$, seis de duração entre 30 minutos e uma hora, três com duração entre uma e duas horas, três com rigidez durante todo o dia e um com duração entre duas horas e quatro horas. Foram aplicados testes para avaliar e diferenciar se havia presença de dor neuropática, $65 \%$ dos participantes tinham o componente neuropático da dor.

Sendo assim, confirma-se que alguns fatores já apontados na literatura, como idade mais avançada, uso de corticoides na fase aguda e subaguda, sexo feminino, funções laborais que sobrecarreguem mais as articulações, são fatores de risco para crônificação das artralgias na infecção pelo chikv. Apesar de não ter sido possível avaliar o uso de terapias complementares, como fisioterapia e acupuntura, todos os participantes em algum momento de evolução da doença afirmaram já ter utilizado de uma ou das duas terapias, relatando melhora logo após os procedimentos, porém com permanência da artralgia e sentindo-se incapacitados em sua grande maioria. 
Dessa forma, pretende-se continuar os estudos da artralgia crônica por chikv e o acompanhamento desses pacientes do estudo na Secretaria Municipal de Saúde, como forma de tentar diminuir o sofrimento e reabilitar esses indivíduos com novas terapêuticas em estudo.

\section{REFERÊNCIAS}

BARRETT, A. D. T.; WEAVER, S. C. Arboviruses: alphaviruses, flaviviruses and bunyaviruses. In: Medical microbiology. 2002.

BETTADAPURA, $\mathrm{J}$ et al. Approaches to the treatment of disease induced by chikungunya virus. The Indian Journal of Medical Research, 2013.

BORGHERINI, G. et al. Outbreak of Chikungunya on Reunion Island: Early Clinical and Laboratory Features in 157 Adult Patients. Clinical Infectious Diseases, v.44, p.1401-1407, 2007.

BRASIL. Ministério da Saúde. Secretaria de Vigilância em Saúde. Departamento de Vigilância das Doenças Transmissíveis. Febre de chikungunya: manejo clínico / Ministério da Saúde, Secretaria de Vigilância em Saúde, Secretaria de Atenção Básica. - Brasília: Ministério da Saúde, 2017.

LEMANT, J et. al. Serious acute chikungunya virus infection requiring intensive care during the Reunion Island outbreak in 2005-2006. Crit Care Med, 2008.

NUNES, M .R. et al. Emergence and potential for spread of Chikungunya virus in Brazil. BMC Med 13, 2015.

PAHO - Pan American Health Organization. Joint WHO/ Number of reported cases of Chikungunya Fever in the Americas - EW3 - (2015w - Cumulative cases). Date MaS, 2016.

PARASHAR, D.; CHERIAN, S. Antiviral Perspectives for Chikungunya Virus. BioMed Research International, vol. 2014. Disponível em: <http://www.hindawi.com/journals /bmri/2014/631642/>. Acesso: 25 Fev 2017.

RODRIGUES F. N. et al. Epidemiology of Chikungunya Virus in Bahia, Brazil, 20142015. Edition 1. PLOS Currents Outbreaks, 2016. Disponívelem: $<$ http://currents.plos.org/ outbreaks/article/epidemiology-of-chikungunya-virus-inbahia-brazil-2014-2015/\#ref12>. Acesso: 25 Fev 2017. 